\title{
Verifying the Chiral Switch of the Pesticide Metolachlor on the Basis of the Enantiomer Composition of Environmental Residues
}

\author{
Thomas Poiger, Markus D. Müller, and Hans-Rudolf Buser*
}

\begin{abstract}
Racemic metolachlor is currently being replaced by $S$-metolachlor, the herbicide enantiomerically enriched with the biologically active (S)-isomers. This 'chiral switch' is expected to reduce the amount of pesticide released into the environment as well as potential side-effects on non-target organisms. The switch is also expected to result in lower environmental concentrations and in a changed enantiomer/stereoisomer composition of the residues. To verify this switch, the enantiomer composition of metolachlor residues from a lake (Baldeggersee, Switzerland) receiving inputs from agricultural activities was measured from 1997 through 2001. Enantioselective GC-MS analyses indicated that pre-1998 inputs into the lake were from the racemic compound. In contrast, more recent inputs showed a clear excess of (S)-isomers, and eventually (2000/2001) consisted almost entirely of the new S-metolachlor. The data document the application of enantio-selective analysis in environmental studies to apportion the relative contributions of old (racemic) and new (enantioenriched) herbicide on the basis of the enantiomer/stereoisomer composition. The data also show a rapid environmental response to the changed composition of a herbicide. In terms of absolute concentrations no direct evidence could be obtained for the replacement because of year-to-year variations in the inputs likely as a result of intensive rainfall during the application periods.
\end{abstract}

Keywords: Chiral pesticides · Chiral switch · Enantioselective analysis · Residue analysis · Surface water

\section{Introduction}

Many pesticides are compounds with at least one element of asymmetry and therefore consist of mixtures of stereoisomers, often with widely differing biological activities [1]. An increasing number of such pesticides, initially marketed as mixtures of stereoisomers or enantiomers, have been introduced in recent years as enantiopure or single-isomer compounds ('chiral switch'). By using enantiopure pesticides, side effects and risks for the environment can be reduced whereas the desired biological activity on the biological target is still maintained.

\footnotetext{
${ }^{*}$ Correspondence: Dr. H.-R. Buser Swiss Federal Research Station $\mathrm{CH}-8820$ Wädenswil Tel.: +41178362 86 Fax: +4117836439

E-Mail: hans-rudolf.buser@faw.admin.ch
}

Metolachlor, 2-chloro-N-[2-ethyl-6-methylphenyl]-N-[2-methoxy-1 methylethyl]acetamide, is an important selective herbicide for use in corn and other crops to control a variety of broad-leaved weeds [2-4]. The compound is one of the most popular pesticides world-wide with an estimated production in excess of 30,000 t/year [5]. Metolachlor has an interesting chemical structure and - due to the presence of two chiral elements (an asymmetrically substituted carbon and a chiral axis) - consists of four stable stereoisomers (Fig. 1). The herbicidal activity is, however, mainly governed by the absolute configuration at the asymmetrically substituted carbon atom in the alkyl moiety [6]. As a matter of fact, $95 \%$ of the herbicidal activity of metolachlor originates from the two $(S)$-isomers $((a S S)$ and $(\mathrm{aRS}))$. Metolachlor was introduced by Ciba-Geigy in 1976 as the racemic compound consisting of equal amounts of active $(S)-((a S S)$ plus $(a R S))$ and inactive $(R)-((a S R)$ plus (aRR)) isomers. Since 1997, rac-metolachlor is being replaced world-wide by $S$-metolachlor with a content of $\sim 90 \%(S)$-isomers and $\sim 10 \%$ $(R)$-isomers and with the same biological effect at $65 \%$ of the use rate [6]. The enantioenriched product is manufactured by Syngenta using a novel enantioselective catalytic process [7]. The 'chiral switch' from racemic to $\mathrm{S}$-metolachlor, as with other chiral pesticides, not only allows lower application rates, it also reduces the amounts of pesticides released into the environment, prevents deployment of inactive isomers ('isomer ballast') to the biosphere, and thus reduces potential side-effects on non-target organisms [8]. The use of the enantiopure compounds should thus lead to lower environmental concentrations and to changed isomer compositions of the residues. Furthermore, the use of enantioenriched products is also beneficial from the viewpoints of production, transport, and handling. In Switzerland, this 'chiral switch' was initiated in 1997 with the registration of $S$-metolachlor followed by the expiration of the registration for the racemic product. 


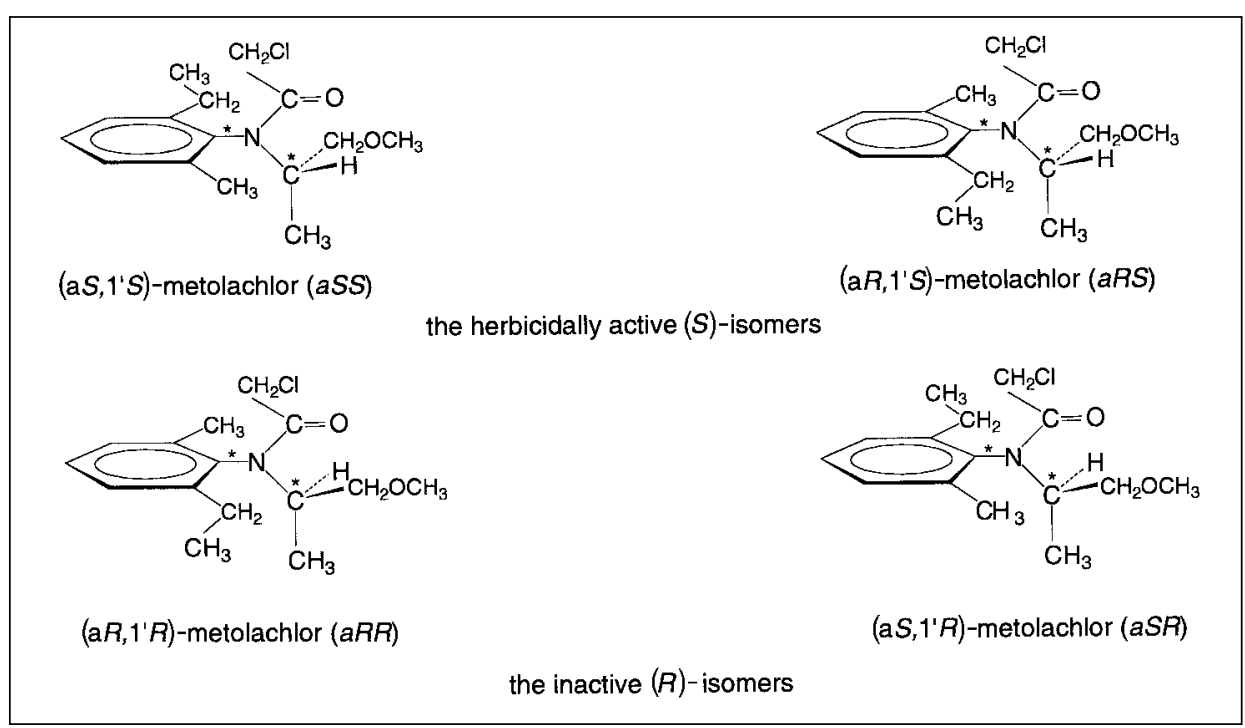

The assessment of side-effects of pesticides such as the potential to contaminate natural waters is an important aspect of any benefit-risk evaluation of pesticides. In this respect, herbicides need particular attention because they are directly applied to soil and thus are more likely to be transported to surface and ground water than other pesticides. Surface run-off from soil seems to be a major process of herbicide input into surface waters [9][10]. Integrated-pest-management measures (IPM), financial incentives for ecological farming, and other measures are expected to result in lower environmental burdens of pesticides. The Federal Office of Agriculture, Bern, Switzerland, initiated a large survey program that includes the monitoring of surface waters in Switzerland for the presence of pesticides to detect trends in concentrations and loads and to correlate these with actual measures taken [11]. Lakes were selected for this program because they are transient reservoirs and reflect the processes in the catchment area, and their composition and properties are less prone to temporal fluctuation than those of rivers and streams (integrating effect). For the program the waters from different lakes in Switzerland (Baldeggersee, Greifensee, Zürichsee, Sempachersee, Murtensee) were selected and some were analyzed at regular (monthly) intervals at the Swiss Federal Research Station, Wädenswil and the Swiss Federal Institute for Environmental Science and Technology, EAWAG, Dübendorf. Mountain lakes, remote from human activities and serving for reference purposes, were included in the campaign. In this article, we present some of these data, in particular on concentrations and the enantiomer composition of the chiral pesticide metolachlor in Baldeggersee, a lake situated in an agricultural

\section{Selection of the Lake Investigated}

Of particular importance for this article is lake Baldeggersee, Switzerland. The lake is located in the central region of Switzerland in an area of intense agricultural activities including corn cultivation, and metolachlor and other pesticides are regularly detected in the waters from this lake. The timespan from 1997 through 2001 covered five application periods of metolachlor, during which the gradual replacement of rac-metolachlor by $S$-metolachlor was expected. Surface water and water from deeper regions (20 m or more) were analyzed at monthly intervals during a 5-year period.

Baldeggersee, as most other Swiss lakes, is stratified during the warmer season (April to October); in winter (November to March) the lake is mixed. Inputs of the pesenantioselective PS086 - BSCD column.
Fig. 1. Structures (absolute configurations) of the four stereoisomers of metolachlor. The asterisks denote the chiral axis and the chiral asymmetrically substituted C-atom.

ticides are expected in spring to early summer into the surface water (epilimnion). Baldeggersee has a mean water residence time (filling time, T) of 3.8 y [12], but a more rapid water exchange in the epilimnion during stratification ( 3 months). Actual amounts of pesticides loaded into the lake (input) depend on a number of parameters, such as the amount of the compounds used in the catchment area, integrated-pest-management (IPM) measures, and actual weather conditions before, during, and following application (intensity, duration, and frequency of rainfall events, flooding of fields, etc.).



Fig. 2. EI SIM chromatograms ( $\mathrm{m} / \mathrm{z} 238$ ) of rac-metolachlor (left-side panel) and S-metolachlor (right-side panel) showing different enantiomer/stereoisomer compositions analyzed using an 
tion between racemic and $S$-metolachlor became possible (Fig. 2 and [14]). The exact enantiomer/stereoisomer composition of metolachlor residues was determined using thermal equilibration followed by enantioselective detection [13]. The enantiomer/stereoisomer composition is expressed as enantiomer excess (EE), defined as the excess of the herbicidally active $(S)$ isomers over the inactive $(R)$-isomers [13]. rac-Metolachlor has an EE of 0 , and $\mathrm{S}$ metolachlor, with $\sim 90 \%$ of $(S)$-isomers and $\sim 10 \%$ of $(R)$-isomers, has an EE of $\sim 0.8$. The simulation of concentrations and enantiomer composition of metolachlor in Baldeggersee was performed as detailed elsewhere [13] using the computer software AQUASIM (EAWAG, Dübendorf, Switzerland; [15]).

\section{Occurrence of Pesticides in Baldeggersee}

Various pesticides are regularly detected at trace (ng/l; parts-per-trillion, ppts) concentrations in some lakes. The concentrations, with the exception of atrazine in some of the lakes, were usually well below the ECE recommended drinking water tolerance level of $100 \mathrm{ng} / \mathrm{l}$. In Baldeggersee, the concentrations of metolachlor in 1997 to 2001 were in the range of 3 to $30 \mathrm{ng} / \mathrm{l}$. As for most of these pesticides, metolachlor showed seasonal changes of the concentration in the lake, and when analyzed enantioselectively, it showed varying stereoisomer composition.

In Fig. 3, we plotted the temporal variation of the metolachlor concentrations in surface water ( 1 and $2.5 \mathrm{~m}$ ) and water from deeper regions (20-30 m) for Baldeggersee over the period 1997 to 2001. The plot shows relatively constant concentrations of metolachlor in the hypolimnion, but concentration peaks in the epilimnion of the lake due to seasonal inputs in spring/early summer, particularly in 1999, 2000, and 2001 when maximum concentrations were up to $30 \mathrm{ng} / \mathrm{l}$. The concentration increases in 1999 to 2001 corresponded to inputs of about $1 \mathrm{~kg}$ in each year. Concentration peaks were also observed for other pesticides, and were for some even larger (e.g. atrazine, maximum concentrations, $250 \mathrm{ng} / \mathrm{l})$. These concentration peaks coincided with the application of metolachlor and other pesticides in the catchment area.

The inputs of pesticides occurred in spring to early summer, at a time when the lake is stratified. The inputs cause a rapid increase of the metolachlor concentration in the epilimnion but, due to the faster flushing in summer (smaller volume affect-

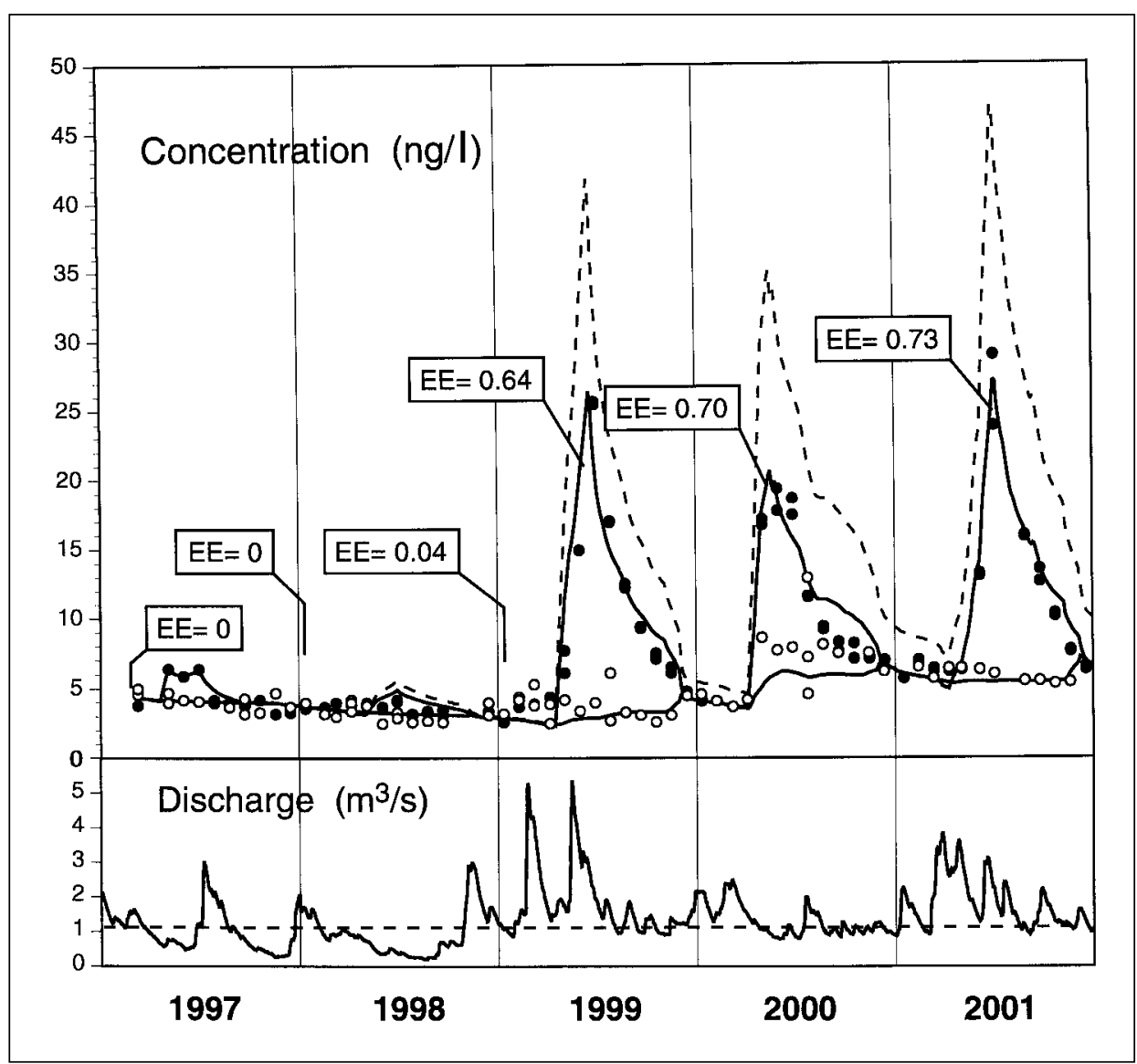

Fig. 3. Concentration of metolachlor in Lake Baldeggersee and enantiomer compositions (EE) measured in surface water (upper panel), and water discharge from Lake Baldeggersee in 1997 to 2001 (lower panel). Symbols: measured concentrations ( $\bullet$, epilimnion; $\bigcirc$, hypolimnion); simulated data ( - concentrations, best fit; ---- predicted concentration for rac-metolachlor with higher use rate. The dashed line in the lower panel indicates the long-term average discharge of Baldeggersee.

ed), metolachlor is rapidly eliminated from the lake via export (dilution). Therefore, in late fall, at the onset of the vertical mixing of the water column, concentrations similar to those prior to the seasonal input are reestablished. The pattern of decreasing concentrations in spring (dilution), followed by concentration increases in spring/early summer (input), followed again by a decrease (dilution/flushing), and mixing of the lake in fall is observed in several Swiss lakes receiving inputs from agricultural activities [16]. A significant part of the pesticides are eventually exported from the lake.

The year-to-year variation of inputs to the lake depends on actual run-off conditions and thus on the rainfall prior to and immediately following application of the pesticide. The inputs are thus subject to variation both regionally and annually. The precipitation data from a nearby meteorological station was complex with many individual rain events of different intensity and duration throughout the study period (data not shown). It is therefore difficult to link individual rain events to the actual pesticide input. However, the precipitation in the catchment area is reflected in the water discharge from the lake (Fig. 3). This discharge shows considerable fluctuations during the study period. A comparison with the long-term average discharge (see dotted line) shows that the discharge in 1997 and 1998 , on average, was below the long-term average ('dry years'), whereas in 1999 to 2001, it was considerably higher ('wet years'). Moreover, peak discharges in 1997 and 1998 were outside the application period of metolachlor, whereas they preceded and/or coincided with the application period in 1999 to 2001. In 1999, the exceptional discharge resulted from particularly intensive rainfall events which caused heavy flooding. In contrast, in 2001, frequent, but not as heavy rainfalls provided for permanently wet conditions with saturated soil conditions. Both situations are expected to favour pesticide input to rivers and lakes via surface runoff. 


\section{Enantiomer Composition of Meto- lachlor Residues in Baldeggersee}

The water from Baldeggersee showed a nearly racemic composition prior to the major input in 1999, followed by a clear change toward a non-racemic composition after this input. The surface water (depth, $2.5 \mathrm{~m}$ ) during the peak inputs in 2000 and 2001 showed a stereoisomer composition very close to that of $S$-metolachlor and clearly different from that of rac-metolachlor.

In Fig. 4 we show chromatograms of surface water from Baldeggersee, analyzed using enantioselective GC-MS. The chromatograms show that the enantiomer composition of the residues in Baldeggersee prior (March) to the input in 1999 was racemic. In July 1999, during the time of major input, this composition was changed and showed a clear excess of $(S)$-isomers. Eventually, chromatograms of the major inputs in 2000 and 2001 show compositions virtually identical to that of $S$-metolachlor. The chromatograms clearly document the changing enantiomer composition of metolachlor in the lake, verifying that racemic metolachlor was replaced by $S$-metolachlor.

It can be assumed that the concentrations of metolachlor in the lake would have been larger if solely the racemic compound with a higher use rate had been used (additional input of $(R)$-isomers). From the concentration and the enantiomer composition actually measured in the lake ( $c_{\text {meas }}, \mathrm{EE} \geq 0$ ), the predicted concentration $\left(\mathrm{c}_{\text {pred }}\right)$ is calculated as

$$
c_{\text {pred }}=c_{\text {meas }}(1+E E)
$$

This concentration is up to 1.78 times higher, when the residues in the lake show contributions of $S$-metolachlor $(\mathrm{EE}=0.78)$. The predicted concentrations calculated in this way are also plotted in Fig. 3 (upper panel, dashed line).

In terms of absolute concentrations of metolachlor in Baldeggersee, no direct evidence could be obtained for a replacement of the racemic by the enantioenriched product in the catchment area of the lake. In fact, concentrations in 1999 to 2001 were similar and even higher than in preceeding years, due to more surface run-off as a result of intensive rainfall during the application period. In addition, use of other herbicides may have gone down in favor of metolachlor-containing products, so that more metolachlor may have been used in the catchment area of the lake, despite the lower application rates. Furthermore, actual herbicide usage depends on the area

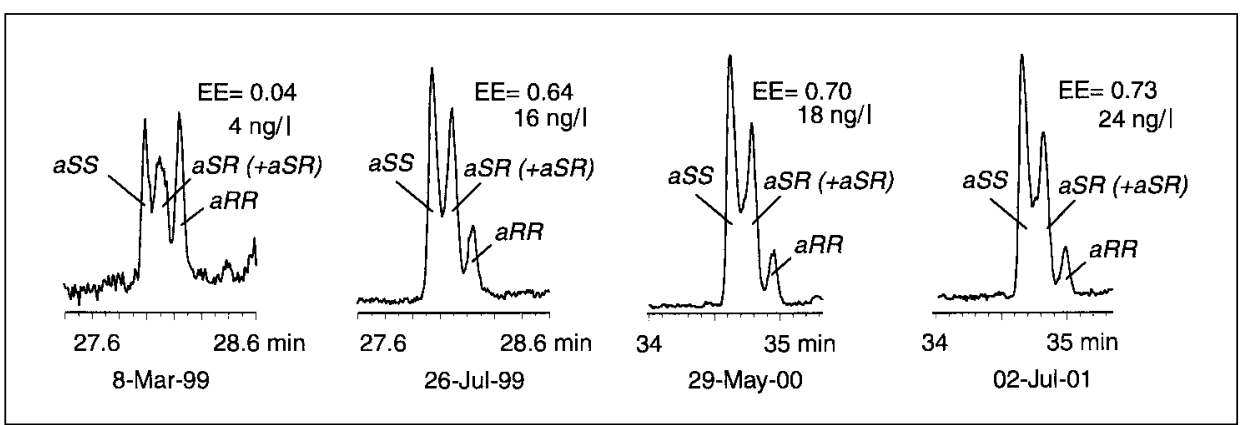

.Fig. 4. EI SIM chromatograms $(\mathrm{m} / \mathrm{z} 238)$ of metolachlor residues in surface water from the Baldeggersee, analyzed using enantioselective PS086-BSCD columns, and showing a racemic composition from earlier applications of racemic metolachlor in March 1999, and non-racemic compositions from increasing contributions of $S$-metolachlor following the peak inputs in 1999 , 2000 and 2001. Note that different columns were used for analyses resulting in different retention times.

treated and type of agricultural production (e.g. corn versus other crops) and is thus also subject to year-to-year variations. Therefore, concentration measurements alone, at least on a short term basis, cannot be used to verify substitution of racemic by $S$-metolachlor.

The enantiomeric composition of the residues, on the other hand, is much less sensitive to these above mentioned factors. The data clearly demonstrate substantial change of the enantiomeric composition of metolachlor residues in the lakes, reflecting the successive replacement of racemic metolachlor by $S$-metolachlor. The data also demonstrate the rapid response of environmental residues to this replacement in terms of enantiomer composition.

\section{Acknowledgment}

We thank the personnel of EAWAG (Dübendorf and Kastanienbaum, Switzerland) for the sampling of Baldeggersee. We also gratefully acknowledge the experienced help of Verena Buser for all sample preparations.

Received: May 4, 2002

[1] A. Williams, Pestic. Sci. 1996, 46, 3-9.

[2] W.A. Ahrens, 'Herbicide Handbook', 7th ed., Weed Society of America, Champaign, IL, 1994.

[3] K.K. Hatzios, 'Herbicide Handbook', Supplement to 7th ed., Weed Society of America, Champaign, IL, 1998.

[4] Anonymous, Environ. Sci. Technol. 1994, 28, 355A.

[5] U.S. Environmental Protection Agency, Office of Pesticide Programs, Washington, D.C. (www.epa.gov/oppbead 1/pestsales).

[6] H. Moser, G.Rihs, H. Sauter, Z. Naturforsch. 1982, 87B, 451-462.

[7] H.U. Blaser, H.P. Buser, K. Coers, R. Hanreich, H.P. Jalett, E. Jelsch, B. Pugin, H.D. Schneider, F. Spindler, A. Wegmann, Chimia 1999, 53, 275-280.
[8] H.R. Buser, M.D. Müller, Neue Zürcher Zeitung, October 17, 2001, p 71.

[9] E.M. Thurman, D.A. Goolsby, M.T. Meyer, M.S. Mills, M.L. Pomes, D.W. Kolpin, Environ. Sci. Technol. 1992, 26, 24402447.

[10] W.E. Pereira, C.E. Rostad, Environ. Sci. Technol. 1990, 24, 1400-1406.

[11] D. Forni, H.U. Gujer, L. Nyffenegger, S Vogel, U. Gantner, Agrar Forschung 1999, 6, 107-110.

[12] P. Liechti, 'Zustand der Seen in der Schweiz'; Bundesamt für Umwelt, Wald und Landschaft (BUWAL), Bern, Switzerland, 1994 (in German).

[13] H.R. Buser, T. Poiger, M.D. Müller, Environ. Sci. Technol. 2000, 34, 2690-2696.

[14] H.R. Buser, M.D. Müller, Environ. Sci. Technol. 1995, 29, 2023-2030.

[15] P. Reichert, Water Sci. Technol. 1994, 30, 21-30.

[16] H.R. Buser, Environ. Sci. Technol. 1990, 24, 1049-1058. 